\title{
Cannabis: An Integrative Update
}

\section{Saurabh Nimesh ${ }^{1 *}$, Pankaj Barman ${ }^{2}$ and Shubham ${ }^{3}$}

${ }^{1}$ Research Scholar Department of Pharmaceutical Technology, Meerut Institute of Engineering and Technology, Meerut (Uttar Pradesh), India ${ }^{2}$ Student, Department of Pharmaceutical Technology, Meerut Institute of Engineering and Technology, Meerut (Uttar Pradesh), India ${ }^{3}$ Senior Veterinary Field Manager; Vet Mankind Pharma Ltd., Haldwani Headquarter (Uttarakhand), India

*Corresponding Author: Saurabh Nimesh, Research Scholar, Department of Pharmaceutical Technology, Meerut Institute of Engineering and Technology, Meerut (Uttar Pradesh), India.

Received: April 25, 2019; Published: May 30, 2019

DOI: $10.31080 /$ ASPS.2019.03.0293

\section{Abstract}

Cannabis Sativa, also known as Indian hemp, is an annual herb of the family Cannabinaceae. Cannabis is a native to Central Asia, and long cultivated in Asia, Europe and China. Plants yielding the drug appear to possess been discovered in India, cultivated for medicative functions as early as 900 before Christ. Currently a day's cannabis is hugely mistreatment as for the habit in India as well as alternative developing countries. Purposed of this article to analyze the consumption, medical specialty studies and clinical trials in conjunction with medicative uses of Cannabis among the individual throughout the world. With the arrival of pharmaceutical cannabis-based medicines (Epidiolex), and easement of access in sure nations, this mental object of cannabis medicine and medical specialty has become indefensible. Natural receptors for mind-altering drug square measure found throughout the organic structure known as the endocannabinoid system. This interest was revived within the 1990's with the outline of cannabinoid receptors and also the identification of associate degree endogenous cannabinoid system within the brain.

Keywords: Receptors; Drug Abuse; Psychopharmacology; Tetrahydrocannabinol Adverse Events

\section{Abbreviations}

CBD: Cannabidiol; EC: Endocannabinoid; GABA: $\gamma$-Aminobutyric Acid; 5-HT: 5-Hydroxytryptamine; 5-HT3: Serotonin Type-3 Receptor, NMDA: n-methyl-d-aspartate, TNF- $\alpha$ : Tumour Necrosis Factor- $\alpha$; THC- Tetrahydrocannabinol; CBN: Cannabinol; OTC: Over The Counter; LSD: Lysergic Acid Diethylamide; MDMA: 3,4-Methylenedioxymethamphetamine; U.S.FDA: United States Food and Drug Administration.

\section{Introduction}

Cannabis is the preferred designation of the plant Cannabis sativa, Cannabis indica, and of minor significance Cannabis Ruderalis (Figure 1) [1]. Cannabis is that the most generally illicitly used substance worldwide and is created in just about each country on them planet. The 2013 World Drug Report calculable that it's employed by 180.6 million folks around the world or $3.9 \%$ of the worldwide population aged 15-64 years [2,3]. The prevalence of cannabis use is anticipated to extend following recent group action of medical and recreational use in many countries worldwide and therefore the introduction of a legal cannabis trade. Cannabis incorporates a long history in India, veiled in legends and religion. The earliest mention of cannabis has been found within the Vedas, or sacred Hindu texts. These writings could be compiled as early as 2000-1400 Before Christ. The Hindu god, Shiva is often related to cannabis, referred to as bhang in India [4-6]. Cannabis has been in style in India since the start of recorded history and is commonly taken as a drink. Bhang is additionally rolled and ingested in tiny balls and different preparations of cannabis in India embody ganja and charas. Stronger than bhang, ganja is formed from the flowers and higher leaves of the feminine plant. 


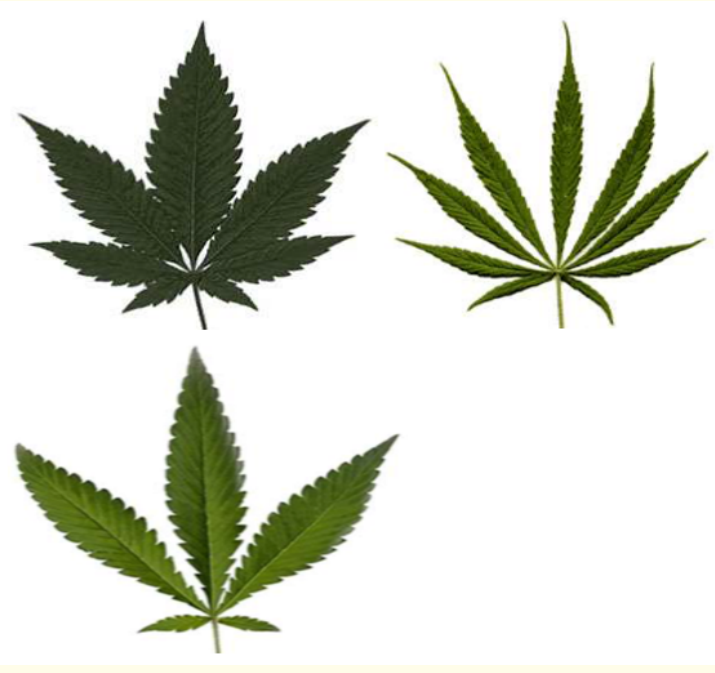

Figure 1: Cannabis Indica, Cannabis Sativa and Cannabis Ruderalis.

Charas is that the strongest preparation and is formed from blooming flowers. Similar in strength to hashish, charas contains a great deal of organic compound (Resin). Each square measure smoke-cured in associate degree ceramic or earthenware pipe referred to as a chillum [7-9]. The British found the utilization of cannabis thus in depth in colonial India, that they commissioned a large-scale study within the late1890s. They were involved that the abuse of cannabis was endangering the health of the native individuals and driving them insane [10]. The British government asked the govt of India to appoint a commission to seem into the cultivation of the hemp plant, preparation of medicine from it, change those medicine, the social and ethical impact of its consumption, and attainable prohibition [11]. The Indian Hemp Drugs Commission Report, completed in 1894, was an Indo-British study of cannabis usage in India. By March 2, 1893, the House of Commons of the United Kingdom was involved with the results of hemp drugs within the province of Bengal, India. The Government of India convened a 7-member commission to seem into these queries, commencing their study on 3 July 1893 [12,13]. Lord Kimberley recommended modifying the scope of the investigation to be distended to incorporate all of India. The report the Commission created was a minimum of 3281 pages long, with testimony from nearly 1200 "doctors, coolies, yogis, fakirs, heads of lunatic asylums, soft drug peasants, tax gatherers, smugglers, army officers, hemp dealers, ganja palace operators and therefore the priesthood [14]. A social science analysis of the report reveals that the commission's visits to asylums everywhere of India helped to undermine the then prevailing belief that consumption of ganja causes mental disease.
The President of the commission was Mr. W. Mackworth Young, and other members include H.T. Ommanney, A.H.L. Fraser, Surgeon-Major C.J.H. Warden, Raja Soshi Sikhareshwar Roy, Kanwar Harnam Singh, and Lala Nihal Chand. Serving as secretary was Mr. H.J. McIntosh (Figure 2) [15]. Over 1000 standardized interviews were conducted throughout Asian country by eminent British and Indian researchers and physicians. The commission was systematic and through. It sampled an oversized and various cluster of individuals in a very of things, from farmers to hospital psychiatrists. After 1 years of careful work, The Indian Hemp Drugs Commission Report produced 6 volumes of data and conclusions. Commissioners were notably involved with whether or not cannabis caused psychoses. After some years of through and well conducted analysis [16]. The Commission all over that suppressing the utilization of flavouring cannabis would be wholly indefensible. They all over that its use is extremely ancient, has some non-secular sanction among Hindus, and is harmless moderately. In fact, additional damage was done by alcohol. What is more, prohibition would be tough to enforce, encourage outcries by non-secular clerics, and probably result in the utilization of additional dangerous narcotics. These findings of The Indian Hemp Drugs Commission Report of 1894 conducted over 100 years a gone, area unit astonishingly relevant these days. Cannabis continues to be obtainable in India of the 20th and 21st centuries. In their review within the mid-50s, Chopra and Chopra (1957) found very little modified since the Indian Hemp Drugs Commission Report of 1894 [17]. Today, bhang is therefore common in some components of India that it will be found in government licenced street stands. In sum, the herbal plant, cannabis, contains a long and continuous history in India. It's lived for 1000 of years in stories of gods and warriors and it continues to measure these days in non-secular ceremonies and street stands [18,19].

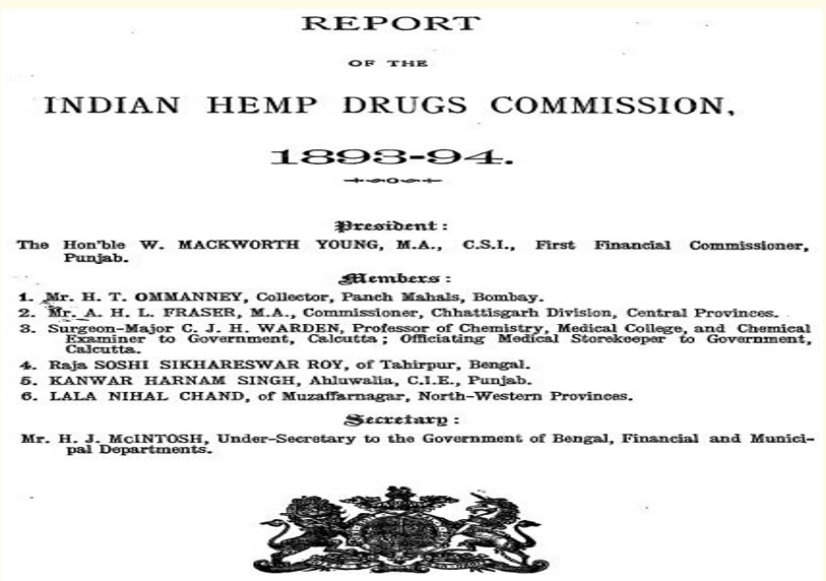

Figure 2: The Indian Hemp Drugs Commission Report. 


\section{Prevalence}

Annual prevalence list of the cannabis uses by country (including some territories) as a proportion of the population aged 1275 years (unless otherwise indicated). The indicator is associate degree annual prevalence rate that is the proportion of the youth and adult population who have consumed cannabis a minimum of once within the past survey year (Table 1) [20].

\begin{tabular}{|c|c|c|c|c|c|c|c|}
\hline S. No. & Country & Prevalence (\%) & Year & S. No. & Country & Prevalence (\%) & Year \\
\hline 1 & Afghanistan & 4.3 & 2010 & 12 & Canada & 12.7 & 2013 \\
\hline 2 & Algeria & 5.7 & 2006 & 13 & Chile & 11.3 & 2014 \\
\hline 3 & Argentina & 7.2 & 2006 & 14 & China & 2.0 & 2000 \\
\hline 4 & Australia & 10.6 & 2007 & 15 & Czech Republic & 15.2 & 2008 \\
\hline 5 & Austria & 3.5 & 2003 & 16 & Germany & 4.8 & 2009 \\
\hline 6 & Bahamas & 5.5 & 2008 & 17 & India & 3.2 & 2000 \\
\hline 7 & Bangladesh & 3.3 & 2004 & 18 & Israel & 27.0 & 2017 \\
\hline 8 & Belarus & 1.1 & 2007 & 19 & Mexico & 1.2 & 2011 \\
\hline 9 & Belgium & 5.1 & 2008 & 20 & Pakistan & 3.9 & 2000 \\
\hline 10 & Bolivia & 4.3 & 2007 & 21 & Sri Lanka & 1.5 & 2000 \\
\hline 11 & Brazil & 2.6 & 2005 & 22 & United States & 16.2 & 2014 \\
\hline
\end{tabular}

Table 1: Information list according to World Drug Report 2011.

\section{Chemical constituents}

The cannabis plant and its merchandise include a massive type of chemicals. The plant contains a minimum of 750 chemicals, among that square measure some 104 totally different cannabinoids. Indian hemp contains $15-20 \%$ of organic compound (present in glandular trichomes) that contains the most important active euphoric principle 1-3-4 trans tetra-hydrocannabinol. It contains oil, trigonelline, and B vitamin. a number of the 483 compounds known square measure distinctive to cannabis; as an example, the quite 60 cannabinoids whereas, the terpenes with concerning 140 members forming the foremost lush category square measure widespread within the Plantae [21]. Cannabis contains over 300 compounds. A minimum of 66 of those square measure cannabinoids, 3 necessary cannabinoids found within the cannabis plant are: (1) Tetrahydrocannabinol, (2) Cannabidiol, (3) Cannabinol (Figure 3).

- Tetrahydrocannabinol: 9-THC cannabinoids with C1 to $\mathrm{C} 5$ side chains are known. The major biogenic antecedent is the THC corrosive A, though THC corrosive B is available to a much lesser degree. THC is the primary psychotropic guideline; the acids are not psychoactive. THC (6a,10a-trans-6a,7,8,10a-tetrahydro-6,6,9-trimethyl3-pentyl-6H-dibenzo [b, d] pyran-1-ol) was initially disconnected in 1942, yet the right structure task by Gaoni and Mechoulam occurred in 1964 [22].

- Cannabidiol: CBD was disengaged in 1940; however, its right structure was initially explained in 1963 by Mechoulam and Shvo. 7-CBD with C1 to C5 side chains has been portrayed. CBD and its comparing corrosive CBDA are the richest cannabinoids in fiber-sort cannabis (mechanical hemp). Secluded in 1955, CBDA was the initially found cannabinoid corrosive [23].

- Cannabinol: 6-CBN-and two CBND-sort cannabinoids are known. With ring $\mathrm{A}$ aromatized, they are oxidation curios of THC and CBD, individually. Their fixation in cannabis items relies on upon age and capacity conditions. CBN was initially named in 1896 by Wood., et al. and its structure illustrated in 1940 [24].<smiles>CCCCCc1cc(O)c2c(c1)OC(C)(C)[C@H]1CCC(C)=C[C@H]21</smiles>

1.THC<smiles>CCCCCc1cc(O)c(C2C=C(C)CCC2C(C)(C)C)c(O)c1</smiles>

2. CBD

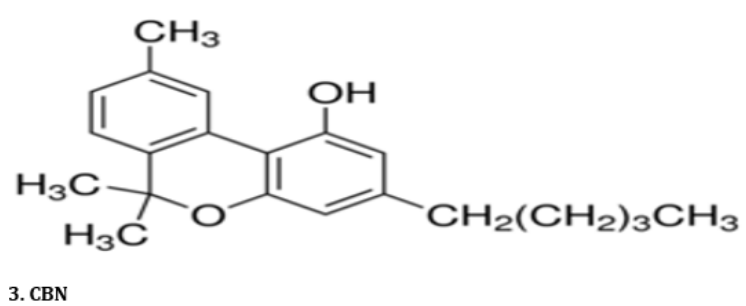

Figure 3: Structure of Tetrahydrocannabinol, Cannabidiol and Cannabinol. 


\section{Pharmacology}

The pharmacology of cannabis is befuddled by the distance of an intensive form of cannabinoids. At very little measurement's, cannabis produces rapture, facilitate of nervousness, sedation and sluggishness. In an exceedingly few regards, the impacts square measure like those caused by liquor. Anandamide has been distinguished because the endogenous matter for the cannabinoid receptor and has pharmacological properties like those of THC. THC is that the primary mind-bending part of cannabis, operating primarily as a weak partial agonist on CB-1 and CB-2 receptors with well-known effects on pain, appetite, digestion, emotions and thought processes mediate through the endocannabinoid system (Figure 4), a physiological state regulator of myriad physiological functions. At the purpose once cannabis is smoke-dried, THC is distinguished in plasma near to inward breath; it's a half-existence of 2 hours. Taking after smoking of what might as well be called 10-15 mg over a time of 5-7 minutes, crest plasma levels of $\Delta 9$-THC are around $100 \mu \mathrm{g} / \mathrm{L}$. It is profoundly lipophilic and broadly disseminated in the body [25]. Two dynamic metabolites are shaped: 11-hydroxy- $\Delta 9$-THC and 8 $\beta$-hydroxy- $\Delta 9$-THC. The first is further metabolized to $\Delta 9$ - THC-11-oic corrosive. Two dormant substances are likewise shaped $-8 \alpha$-hydroxy- $\Delta$-THC and $8 \alpha$, 11-dihydroxy- $\Delta 9$-THC and numerous other minor metabolites, a large portion of which show up in the pee and defecation as glucuronide conjugates. A couple of metabolites is recognized within the pee for up to 2 weeks taking once smoking or intake. There's very little confirmation for damage to organ frameworks among direct clients; but, utilization with tobacco conveys the bigger a part of the hazards of that substance. Most enthusiasm for the unfavorable properties of cannabis has centered on its relationship with dementia praecox, despite the very fact that it's still foggy if there's an inductive association between psychological upbeat and cannabis. Fatalities straight forwardly attributable to cannabis is rare.

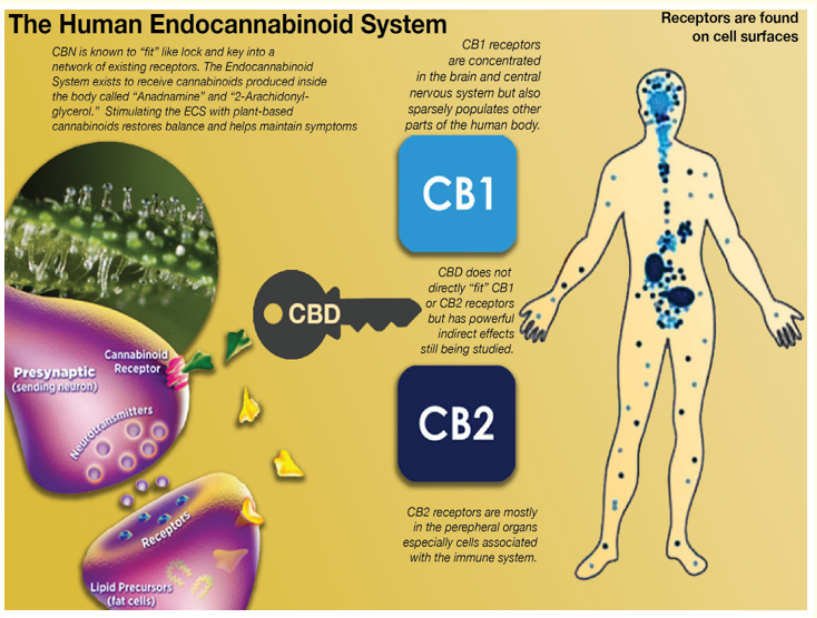

Figure 4: Human endocannabinoid system.
Cannabinoid receptors- CB1

- Location: CNS, Peripheral nervous system, Peripheral tissues

- Effects: Neuromodulatory, Analgesia, Muscle relaxation, Appetite stimulant, Hormonal activity, Impair cognition and memory, Alter motor function

- Ligand: THC, CBD, CBN, Nabilone, Dronabinol.

Cannabinoid receptors- CB2

- Location: Peripheral tissues, Central immune cells

- $\quad$ Effects: Immunosuppressive, Anti-inflammatory

- Ligand: CBD, Nabilone, Dronabinol [26].

The Traditionally use of cannabis for the purposes of healing

In1500 B.C., Earliest written relation to medical Marijuana in Chinese Pharmacopeia; 1213 B.C., Egyptians use cannabis for eye disease, Inflammation, and Enemas; a 1000 B.C., Bhang, a drink of cannabis and milk, is employed in Asian country as an anesthetic. In 1850, cannabis had made its way into the United States Pharmacopeia, a political candidate public normal setting authority for all prescription and over-the-counter medicines, that listed marijuana as treatment for various afflictions, including: neuralgia, tetanus, typhus, cholera, rabies, dysentery, alcoholism, narcotic addiction, anthrax, leprosy, incontinence, gout, convulsive disorders, inflammation, insanity, excessive expelling injury, and female internal reproductive organ injury, among others. In 1928, Cannabis is intercalary to the list of prohibited medicine within the United Kingdom's "Dangerous medicine Act in 1928 and Cocaine was intercalary in 1920" [27].

\section{Scientific basis of Indian cannabis claims}

This chapter has enumerated the lore of Indian medicine with respect to therapeutic benefits of clinical cannabis, but what is its scientific rationale. The issues will be addressed systemically (Table 2) [28].

\section{Adverse Drug Reactions}

Medical use of cannabis and cannabis products have not been reviewed and approved by the U.S. Food and Drug Administration. Information on side effects/adverse reactions in limited (Table 3) [29].

\section{Studies and clinical trials}

PubMed references over 20000 printed studies or reviews beneath the search terms cannabis, cannabinoid or marijuana, nearly half that were printed at intervals the last 5 years; as supported by surveys, case-based studies, anecdotal self-reports, laboratory-based short trials (Table 4). Proof from clinical trials is given below with sources from primary manuscripts and 10 meta-analyses [30]. 


\begin{tabular}{|c|c|c|}
\hline S. No. & Indication & Physiological basis \\
\hline \multirow[t]{5}{*}{1} & \multicolumn{2}{|l|}{ Psychiatric: } \\
\hline & Anxiety & CBD reduces anxiety in humans \\
\hline & Extinction of aversive memories & EC control in hippocampus \\
\hline & Insomnia & Increased sleep in pain/multiple sclerosis patients \\
\hline & Addiction treatment & Decreased usage of cocaine/alcohol \\
\hline \multirow[t]{4}{*}{2} & \multicolumn{2}{|l|}{ Infectious: } \\
\hline & Antibiotic & Effects of cannabinoids/terpenoids \\
\hline & Anti-malarial & Caryophyllene, $\alpha$-terpineol \\
\hline & Insecticidal/pediculicidal & Octopamine/GABA \\
\hline \multirow[t]{3}{*}{3} & \multicolumn{2}{|l|}{ Dermatological: } \\
\hline & Anti-psoriatic & TNF- $\alpha$ antagonism \\
\hline & Anti-pruritic & Peripheral anti-nociception \\
\hline \multirow[t]{6}{*}{4} & \multicolumn{2}{|l|}{ Neurological: } \\
\hline & Neuropathic pain & EC modulation of CNS pathways, Clinical pain reduction \\
\hline & Muscle relaxation & Spinal interneuron effects \\
\hline & Neuroprotection & THC/CBD antioxidant/NMDA antagonism \\
\hline & Migraine & Effects on periaqueductal grey, 5-HT, inflammation \\
\hline & Seizures & $\begin{array}{l}\text { CBD anticonvulsant, THC anticonvulsant, EC modulation of seizure } \\
\text { threshold }\end{array}$ \\
\hline \multirow[t]{2}{*}{5} & \multicolumn{2}{|l|}{ Rheumatic: } \\
\hline & Benefit in rheumatoid arthritis & TNF- $\alpha$ antagonism \\
\hline \multirow[t]{3}{*}{6} & Oncological: & \\
\hline & Anti-nausea & 5-HT3 antagonism or other \\
\hline & Tumour reduction & $\begin{array}{l}\text { Promotes apoptosis, reduces angiogenesis, Anti-prolactin effect, } \\
\text { Blocks pulmonary carcinogenesis }\end{array}$ \\
\hline \multirow[t]{2}{*}{7} & \multicolumn{2}{|l|}{ Endocrinological: } \\
\hline & Appetite stimulation & Hypothalamic effect \\
\hline \multirow[t]{2}{*}{8} & \multicolumn{2}{|l|}{ Pulmonary: } \\
\hline & Asthma & Bronchodilation \\
\hline \multirow[t]{3}{*}{9} & Sexual: & \\
\hline & Impotence & Pain reduction/spinal effects \\
\hline & Premature ejaculation & EC modulation \\
\hline \multirow[t]{4}{*}{10} & Gynaecological: & \\
\hline & Dysmenorrhea & Smooth muscle relaxation \\
\hline & Uterine bleeding & EC modulation in uterus \\
\hline & Lower-urinary-tract symptoms & Increased bladder capacity, decreased incontinence \\
\hline
\end{tabular}

Table 2: Indications for cannabis. 


\begin{tabular}{|l|l|l|}
\hline S. No. & System & Effects \\
\hline 1 & Cardiorespiratory & $\begin{array}{l}\text { Tachycardia, bradycardia, vasodilation, orthostatic, hypotension, coughing, and airway } \\
\text { obstruction }\end{array}$ \\
\hline 2 & Central Nervous System & $\begin{array}{l}\text { Euphoria, dysphoria, anxiety, heightened sensory, perception, drowsiness, sleep, } \\
\text { memory impairment, psychosis, and cognitive impairment }\end{array}$ \\
\hline 3 & Immune system & Impaired bactericidal activity \\
\hline 4 & Eye & Decreased intraocular pressure \\
\hline
\end{tabular}

Table 3: Reported adverse reactions.

\begin{tabular}{|l|c|c|c|}
\hline S. No. & Diseases & Evidence \\
\hline 1 & Cancer & $\begin{array}{r}\text { On balance, whereas there's wonderful proof of anti-cancer properties in vitro (human cell lines) } \\
\text { and in vivo (animal) studies, there's very little proof of actual leads to humans except within the } \\
\text { treatment of basal cell malignant neoplastic disease. However, few would disagree that the pallia- } \\
\text { tive worth of cannabis is of nice profit to several cancer patients. }\end{array}$ \\
\hline 2 & $\begin{array}{r}\text { Multiple } \\
\text { Sclerosis }\end{array}$ & $\begin{array}{r}\text { There is a transparent agreement amongst scientists and doctors that cannabis is safe and effec- } \\
\text { tive as a palliative treatment for induration. Additional promising analysis is current into whether } \\
\text { or not cannabis could have a curative impact by promoting repair of the myelin sheath. }\end{array}$ \\
\hline 3 & $\begin{array}{c}\text { Chronic Pain } \\
\text { There is a large quantity of good quality evidence, including clinical trials with placebo controls, } \\
\text { that demonstrate the efficacy and safety of cannabis in treating chronic pain }\end{array}$ \\
\hline 4 & $\begin{array}{r}\text { Alzheimer's } \\
\text { Disease }\end{array}$ & $\begin{array}{r}\text { The evidence is strong that regular, moderate use of cannabis helps to delay the onset and pro- } \\
\text { gression of Alzheimer's disease and other neurodegenerative conditions. }\end{array}$ \\
\hline 5 & $\begin{array}{r}\text { Disease } \\
\text { Recent clinical trials have made dramatic results with 50\% of Crohn's patients achieving complete } \\
\text { remission and over 90\% achieving substantial improvement. The proof for the employment of } \\
\text { cannabis in Crohn's, gut illness and alternative types of inflammatory bowel disease is conclusive. }\end{array}$ \\
\hline
\end{tabular}

Table 4: Clinical trial evidence of cannabis for medicinal use.

U.S. Food and Drug Administration approved the first-ever prescription drug made from cannabis

The USFDA on 25 June 2018 approved the "Epidiolex" (cannabidiol) oral resolution (Figure 5) for the treatment of seizures related to 2 rare and severe brain disorder (epilepsy), Lennox-Gastaut syndrome and Dravet syndrome, in patients 2 years old age and older. Epidiolex is the first medical drug made from marijuana and created by United Kingdom Biopharma Company 'GW Pharmaceuticals'. Though many states have legalized the medical and recreational use of marijuana, the administrative body had nevertheless to try to therefore till nowadays. Below the Controlled Substances Act, marijuana could be a Schedule-I drug, which means it's a high potential for abuse and no recognized medical purpose (heroin, LSD, and methylenedioxymethamphetamine also are Schedule-I drugs) [31]. The active ingredient in Epidiolex, a brain disorder medication, is CBD, one amongst the 2 main chemical compounds found in marijuana. While CBD has purely medicinal purposes, the other compound, THC, is what provides marijuana users the psychoactive effects commonly associated with the plant ordinarily related to the plant. Epidiolex contains less than $0.1 \%$ of THC. An FDA advisory panel recommended the approval of Epidiolex last April, specifically for the treatment of Lennox-Gastaut syndrome and Dravet syndrome. The FDA said, "The most common side effects that occurred in Epidiolex-treated patients in the clinical trials were: sedation and lethargy, elevated liver enzymes, decreased appetite, diarrhea, rash, fatigue, malaise and weakness, insomnia, sleep disorder and infections". Whereas the FDA had not antecedently approved any drug directly account from marijuana, it's marketed some containing an artificial version of THC. In step with the agency's website, the FDA is aware that there's goodish interest in mari- 
juana's use to aim to treat variety of medical conditions, including, as an example, glaucoma, AIDS wasting syndrome, neuropathic pain, cancer, degenerative disorder, chemotherapy-induced nausea, and bound seizure disorders [32].

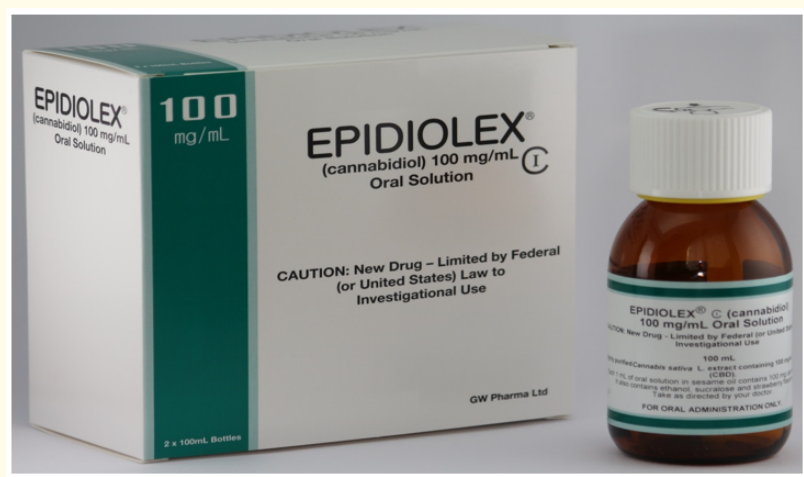

Figure 5: Marketed preparation of Cannabidiol from U.K. Biopharma Company GW Pharmaceuticals.

\section{Conclusion}

Cannabinoid drugs, in both organic and synthetic forms became increasingly popular despite the potential harms associated with their use. Cannabis clearly offers important therapeutic advantages for a good vary of conditions while not substantial risks or unmanageable facet effects. It's essential that clinicians gain a larger understanding of their materia medica, dosing and administration to maximize therapeutic potential and minimize associated issues. government agency can still support development of specific new medication that are safe, effective, and made to a top quality. Drug development grounded in rigorous research project is crucial to decisive the suitable uses of marijuana within the treatment of human sickness. Numerous countries are revamping their national policies for supporting use of cannabis for therapeutic functions. Indian medical fraternity ought to urge the Indian government to facilitate analysis to explore medical and biological process potential of this versatile native plant.

\section{Acknowledgement}

The authors are thankful to the Mr. Jivan Kumar; Production officer of Kusum Healthcare Pvt. Ltd. Chopanki, Bhiwadi (Rajasthan) India, for her support and helpful in cooperation in the review and data collection process.

\section{Conflict of Interest}

The authors declare that there is no conflict of interest regarding the publication of this paper.

\section{Bibliography}

1. Ebbert JO., et al. "Medical Cannabis". Mayo Clinic Proceedings 93 (2018): 1842-1847.

2. Wadsworth E., et al. "Differences in patterns of cannabis use among youth: prevalence, perceptions of harm and driving under the influence in the USA where non-medical cannabis markets have been established, proposed and prohibited". Drug and Alcohol Review 37.7 (2018): 903-911.

3. Hammond D., et al. "International differences in patterns of cannabis use among youth: prevalence, perceptions of harm, and driving under the influence in Canada, England and United States". Addictive Behaviors 90 (2019): 171-175.

4. Wang GS., et al. "Impact of marijuana legalization in Colorado on adolescent emergency and urgent care visits". Journal of Adolescent Health 63.2 (2018): 239-241.

5. Rusby JC., et al. "Legalization of recreational marijuana and community sales policy in Oregon: impact on adolescent willingness and intent to use, parent use, and adolescent use". Psychology of Addictive Behaviors 32.1 (2018): 84-92.

6. Fantegrossi WE., et al. "Pro- psychotic effects of synthetic cannabinoids: interactions with central dopamine, serotonin, and glutamate systems". Drug Metabolism Reviews 50.1 (2018): 65-73.

7. Mustonen A., et al. "Adolescent cannabis use, baseline prodromal symptoms and the risk of psychosis". British Journal of Psychiatry 212.4 (2018): 227-233.

8. Murray RM., et al. "Cannabis associated psychosis: neural substrate and clinical impact”. Neuropharmacology 124 (2017): 89-104.

9. Jongsma HE., et al. "Treated incidence of psychotic disorders in the multinational EUᄀGEI study". JAMA Psychiatry 75.1 (2018): 36-46.

10. Potter DJ., et al. "Potency of $\Delta^{9} \neg$ tetrahydrocannabinol and other cannabinoids in cannabis in England in 2016: implications for public health and pharmacology". Drug Testing and Analysis 1.40 (2018): 628-635. 
11. Freeman TP., et al. "Changes in cannabis potency and first-time admissions to drug treatment: a 16-year study in the Netherlands". Psychological Medicine 48.14 (2018): 2346-2352.

12. Piper BJ., et al. "Substitution of medical cannabis for pharmaceutical agents for pain, anxiety, and sleep". Journal of Psychopharmacology 31.5(2017): 569-575.

13. Gage SH., et al. "Assessing causality in associations between cannabis use and schizophrenia risk: a two-sample Mendelian randomization study". Psychological Medicine 47.5 (2017): 971-980.

14. Kindred JH., et al. "Cannabis use in people with Parkinson's disease and Multiple Sclerosis: A web-based investigation". Complementary Therapies in Medicine 33 (2017): 99-104.

15. MacCallum CA., et al. "Practical considerations in medical cannabis administration and dosing". European Journal of Internal Medicine 49 (2018): 12-19.

16. Fischer B., et al. "Lower-risk cannabis use guidelines: A comprehensive update of evidence and recommendations". American Journal of Public Health 107 (2017): 1-12.

17. Stith SS., et al. "Patient-reported symptom relief following medical cannabis consumption". Frontiers in Pharmacology 9 (2018): 916.

18. Vigil JM., et al. "Effectiveness of raw, natural medical Cannabis flower for treating insomnia under naturalistic conditions". Medicines 5.3 (2018): 75.

19. Blundell M., et al. "A cloud on the horizon-a survey into the use of electronic vaping devices for recreational drug and new psychoactive substance (NPS) administration". QJM 111.1 (2018): 9-14.

20. Richards JR. "Cannabinoid hyperemesis syndrome: Pathophysiology and treatment in the emergency department". Journal of Emergency Medicine 54.3 (2018): 354-363.

21. Śledziński P., et al. "The current state and future perspectives of cannabinoids in cancer biology". Cancer Medicine 7.3 (2018): 765-775.

22. "Michigan just became the 10th state to legalise marijuana. Here's where marijuana won and lost in the midterms". Business Insider (2018).
23. "FDA Approves Epidiolex (cannabidiol) to Treat LennoxGastaut Syndrome and Dravet Syndrome”. Drugscom (2018).

24. "Justice Department Issues Memo on Marijuana Enforcement". The US Department of Justice (2018).

25. "American Academy of Ophthalmology Reiterates Position that Marijuana is Not Proven Treatment for Glaucoma". (2017).

26. "Monitoring the Future 2016 Survey Results". National Institute of Drug Abuse (NIDA)". (2017).

27. "American College of Obstetrics and Gynecology (ACOG). Marijuana Use During Pregnancy and Lactation". (2017): 722.

28. Delkic M. "How Jeff Sessions plans to end medical marijuana before the year is over". Newsweek (2017).

29. "Marijuana and heart health: What you need to know". Harvard Health Publishing (2017).

30. “National Conference of State Legislatures (NCSL)". State Medical Marijuana Laws (2017).

31. "World Health Organization. Essential medicines and health products: forty-first meeting of the Expert Committee on Drug Dependence". (2018).

32. For Alternative Approaches to Addiction, Think and Do Tank (FAAAT). Breaking news: WHO changes position on medical cannabis after 60 years". (2019).

\section{Volume 3 Issue 6 June 2019}

\section{(c) All rights are reserved by Saurabh Nimesh., et al.}

